\title{
Prognostic significance of anaplastic lymphoma kinase rearrangement in patients with completely resected lung adenocarcinoma
}

\author{
Yinglei Liu, Xiangyun Ye, Yongfeng Yu, Shun Lu \\ Shanghai Lung Cancer Center, Shanghai Chest Hospital, Shanghai Jiao Tong University, Shanghai 200030, China \\ Contributions: (I) Conception and design: All authors; (II) Administrative support: None; (III) Provision of study materials or patients: None; (IV) \\ Collection and assembly of data: All authors; (V) Data analysis and interpretation: All authors; (VI) Manuscript writing: All authors; (VII) Final \\ approval of manuscript: All authors. \\ Correspondence to: Shun Lu. Shanghai Lung Cancer Center, Shanghai Chest Hospital, Shanghai Jiao Tong University, 241 West Huaihai Road, Xuhui \\ District, Shanghai 200030, China. Email: shunlu@sjtu.edu.cn.
}

Background: Reports of the prognostic significance of anaplastic lymphoma kinase (ALK) rearrangement
in early stage lung adenocarcinoma have been contradictory. This study aimed to identify the associations of
ALK rearrangement with clinicopathologic features and prognosis in patients with surgically resected stage I-
IIIA lung adenocarcinoma.

Methods: Analysis of $A L K$ status was performed by a fully-automated immunochemistry assay (with rabbit monoclonal Ventana D5F3 antibody) in tissue sections of 2,103 patients with surgically-resected stage IIIIA lung adenocarcinoma. $A L K$ positive patients were matched with negative patients in a 1:1 ratio using propensity score matching (PSM). Clinical outcomes were assessed by disease-free survival (DFS) and overall survival (OS) after surgery. Initial recurrence pattern was also investigated according to ALK status.

Results: Among 2,103 stage I-IIIA lung adenocarcinoma cases, 81 (3.9\%) were $A L K$ positive. $A L K$ positivity was significantly associated with younger age $(\mathrm{P}<0.001)$, solid predominant adenocarcinoma $(\mathrm{P}<0.001)$, variants of invasive adenocarcinoma $(\mathrm{P}<0.001)$, higher frequency of pleura invasion $(\mathrm{P}=0.040)$, smaller tumor size $(\mathrm{P}=0.014)$, mediastinal lymph node involvement $(\mathrm{N} 2 ; \mathrm{P}<0.001)$ and later pathologic stage (IIIA; P=0.001). In the match cohort, $A L K$ positivity was not associated with DFS [hazard ratio (HR), 0.58; 95\% confidence interval (CI): 0.33-1.03, P=0.063] or OS (HR, 0.61; 95\% CI: 0.22-1.67, P=0.334). Lymph node involvement (HR: 5.36, 95\% CI, 3.01-9.65, $\mathrm{P}<0.001$ ) and solid predominant adenocarcinoma subtype (HR, 2.02; 95\% CI: 1.07-3.79; P=0.029) were the independent prognostic factors of inferior DFS, and lymph node involvement was the independent prognostic factors of worse OS (HR, 6.61; 95\% CI: 2.43-17.94; $\mathrm{P}<0.001)$. ALK positive patients had a higher risk of developing tumor recurrence in liver $(\mathrm{P}=0.043)$.

Conclusions: $A L K$ rearrangement was not an independent prognostic factor in stage I-IIIA lung adenocarcinoma patients but leaded to a higher risk of developing recurrence in liver.

Keywords: Anaplastic lymphoma kinase rearrangement ( $A L K$ rearrangement); lung adenocarcinoma; postoperative recurrence; prognosis

Submitted Apr 26, 2019. Accepted for publication Sep 12, 2019.

doi: $10.21037 /$ jtd.2019.09.65

View this article at: http://dx.doi.org/10.21037/jtd.2019.09.65

\section{Introduction}

Lung cancer is the most commonly diagnosed cancer (11.6\% of the total cases) and the leading cause of cancer death (18.4\% of the total cancer deaths) (1). Two main types of lung cancer are small cell lung cancer (SCLC) $(10-15 \%)$ and non-small cell lung cancer (NSCLC) 
(80-85\%) (2). NSCLC is subdivided into adenocarcinoma, squamous cell carcinoma (SQCC) and large cell carcinoma. Adenocarcinomas include adenocarcinoma in situ (AIS), minimally invasive adenocarcinoma (MIA), invasive adenocarcinoma and variants of invasive adenocarcinoma. Both AIS and MIA are associated with good prognosis.

The patient with anaplastic lymphoma kinase (ALK) gene rearrangement, which is caused by the translocation or inversion of chromosome $2 \mathrm{p}$, is an important patient subset of lung cancer. The prevalence of $A L K$ positive patients has been reported to range from $3 \%$ to $7 \%$ in advanced NSCLC (3-6), and $2.3 \%$ to $8.6 \%$ in early stage NSCLC (7-14). ALK positivity is correlated with adenocarcinoma histology, particularly the solid and signet ring pattern; never or light/former smoking status; younger age; and wild type for EGFR or KRAS gene mutation (5,15-19).

$A L K$ was first discovered in 1994 as a fusion oncogene with nucleophosmin (NPM) in a subset of anaplastic largecell lymphomas (ALCLs) (20). However, it was not until 12 years ago that interest in $A L K$ surged after the discovery of a novel $A L K$ fusion-echinoderm microtubule-associated protein-like 4 (EML4)- $A L K$, a somatic gene rearrangement found in a small portion of Japanese lung cancers (21). $E M L 4-A L K$ is formed by an inversion occurring on the short arm of chromosome 2 involving the genes encoding $A L K(2 \mathrm{p} 23)$ and EML4 (2p21) with variants 1, 2, and $3 \mathrm{a} / 3 \mathrm{~b}(22,23)$. The three major variants (v1: E13; A20, v2: E20; A20, and v3; E6; A20) account for more than $90 \%$ of lung cancers associated with $E M L 4-A L K$. In addition to EML4-ALK, several other $A L K$ fusions have been reported, including $T R K$-fused gene (TFG)-ALK, kinesin family member 5B (KIF5B)-ALK and kinesin light chain 1 (KLC1)-ALK $(15,24,25)$. At the cellular level, $A L K$ regulates canonical signaling pathways that are shared with other receptor tyrosine kinases (RTK) including RAS-mitogenactivated protein kinase (MAPK), phosphoinositide 3-kinase (PI3K)-AKT, and JAK-STAT pathways (26). In $A L K$ rearrangements, $5^{\prime}$ end partners such as EML4 and $N P M$ are fused to the intracellular tyrosine kinase domain of $A L K$. The domains in the partner proteins promote dimerization and oligomerization of the fusion proteins, inducing constitutive activation of the $A L K$ kinase and its downstream signaling pathways. This leads to uncontrolled cellular proliferation and survival. The EML4-ALK fusion gene possesses powerful oncogenic activity, both in vivo and in vitro $(21,27)$, which might result in poor prognosis of NSCLC. However, several published studies show the conflicting results about the prognostic value of $A L K$ rearrangement in NSCLC (7-14,28-31). Tantraworasin (10), Paik (8), Fukui (29), and Ohba (12), demonstrated that $A L K$ positivity was not correlated with prognosis. Conversely, five reports revealed that patients with $A L K$ rearrangement NSCLC had a shorter DFS $(7,9,13,14,28)$. In contrast, Blackhall et al. reported superior RFS and OS in patients with $A L K$ positive early-stage NSCLC (11). Preclinical studies demonstrate that $A L K$-driven lung cancers are addicted to $A L K$ and highly sensitive to $A L K$ inhibition $(27,32)$, indicating that $A L K$ rearrangement is a predictive factor for the therapeutic effect of $A L K$ inhibitors. Additionally, several $A L K$ inhibitors are already approved for the first line treatment of advanced stage $A L K$-positive NSCLC due to their encouraging therapeutic effect (33-36). The prognostic value of ALK rearrangement will help guide management and formulate statistical assumptions in the design of future ALK inhibitor- based adjuvant clinical trials. However, the prognostic significance of $A L K$ rearrangement remains unclear and further investigation is needed.

The major objectives of the present study are not only to compare the clinical outcomes of $A L K$-positive versus $A L K$-negative completely resected stage I-IIIA lung adenocarcinoma patients, but also to explore the correlation of ALK rearrangement with clinical characteristics.

\section{Methods}

\section{Study population and data collection}

In our study, 2,103 patients with pathological stage I-IIIA lung adenocarcinoma who underwent complete resection in Shanghai Chest Hospital between July 2013 and December 2014, with at least 4 years of follow-up were included in the study. The patients who received neoadjuvant chemotherapy or radiotherapy were excluded. The patients did not receive $A L K$-targeted therapy before tumor recurrence in our study cohort. Histological types of lung adenocarcinoma are determined according to 2015 WHO classification of lung adenocarcinoma. The predominant pattern was defined as the pattern with the largest percentage. Lung cancer pathologic staging of the patients was based on the 8th edition of the TNM classification. All patients' clinicopathologic characteristics were collected from the medical recording system. This study was approved by Ethics Committee of Shanghai Chest Hospital Jiao Tong University. 


\section{Detection of ALK rearrangement}

Immunohistochemistry (IHC) was performed for all patients on 5- $\mu \mathrm{m}$ thick formalin-fixed paraffin-embedded surgical specimens with the fully-automated Ventana IHC system using the D5F3 anti-ALK rabbit monoclonal primary antibody in a Bech-mark XT staining module (Ventana Medical Systems, Illkirch Graffenstaden, France). The $A L K$ status was described by a binary scoring system, either $A L K$ positive or $A L K$ negative. The histopathologic types and $A L K$ status were evaluated independently by two experienced pathologists of Shanghai Chest Hospital.

\section{Clinical outcomes and statistical analysis}

Clinical outcomes were presented by overall survival (OS), defined as the time interval from date of surgery to death from any cause; disease-free survival (DFS), defined as the time from date of surgery to disease recurrence or death from any cause. If recurrence or death was not observed, the censoring date was the last day of follow-up. Both OS and DFS were calculated in months.

Statistical analyses were performed using SPSS ${ }^{\circledR}$, version 24.0 (SPSS Inc., Chicago, IL, USA). Comparison of clinical characteristics according to $A L K$ status was performed using Mann-Whitney $U$ tests (continuous variables) and chisquare tests or Fisher's exact tests (categorical variables).

Association between time-to-event outcomes and $A L K$ status is only explored in $A L K$ matched cohort. For this cohort, survival was estimated by the Kaplan-Meier method and compared using the log-rank test. The median followup time was estimated using the reverse censoring method for OS. Cox proportional hazards regression analysis was used to calculate the hazard ratio (HR) and $95 \%$ confidence interval (CI). Multivariable Cox regression, with the backward elimination procedure (removal criterion of $10 \%$ ), was used to choose the best model for DFS and OS, examining characteristics including sex, age at surgery, smoking status, pathologic tumor stage ( $\mathrm{pT}$ stage), pathologic nodal stage ( $\mathrm{pN}$ stage), adenocarcinoma subtypes and $A L K$ status. In all analyses, two-tailed $\mathrm{P}<0.05$ was considered statistically significant.

\section{Propensity score matching (PSM)}

PSM was used to control for confounding effects of known predictors for lung cancer progression or recurrence. PSM was carried out in stage IA, IB, IIA, IIB, IIIA cohort respectively to guarantee the exact balance of pathologic stage, which was considered to be the most important prognostic factor, between $A L K$ positive and $A L K$ negative patients in the matched cohort. Propensity scores for all patients were calculated by using a multiple logistic regression with the following covariates: age, sex, type of surgery, histological subtypes and pleura invasion status. In the $A L K$ matched cohort, all $81 A L K$ positive patients were matched 1:1 with $81 A L K$ negative patients. The clinical characteristics baseline before and after PSM were shown in Table S1.

\section{Follow up}

The follow-up data of the matched cohort were obtained by official contact with patients or their relatives by telephone or collected from hospital records. In the matched cohort of 162 patients, seven patients lost contact after surgery in the $A L K$ positive group, and 8 patients in the $A L K$ negative group. The workflow of the determination of the $A L K$ status and the populations identified is depicted in Figure 1.

Routine examinations, such as a plain chest X-ray; computed tomography scan of the thorax, head, and abdomen; and ultrasound of neck and abdomen, were generally performed every 3 months for the first 2 years after surgery and every 6 months after that for 5 years. After 5 years, the patients were assessed annually. Bone scans were performed as clinically indicated on the basis of bone pain. Positron emission tomography and bronchoscopy with biopsy were performed at the treating physician's discretion.

The follow-up period was completed in December 2018 or to the death date of patients. The median follow-up was 55.3 months (interquartile range, 51.6 to 60.2 months).

\section{Results}

\section{Clinicopathologic characteristics of ALK positive patients}

The clinicopathologic characteristics of 2,103 completelyresected stage I-IIIA lung adenocarcinoma patients are shown in Table 1. Eighty-one (3.9\%) of the 2,103 patients were $A L K$ positive. Eight hundred and ninety patients (42.3\%) were male, and $1,213(57.7 \%)$ were female; age (year) at surgery ranges from 24 to 83 . A total of 1,840 (87.5\%) were never-smokers, 252 (12.0\%) were smokers, and $11(0.5 \%)$ patients' smoking status were unknown. Tumor size $(\mathrm{cm})$ ranged from 0.2 to 15.0 . The pathologic stage was stage I in 1,639 patients (77.9\%), stage II in 


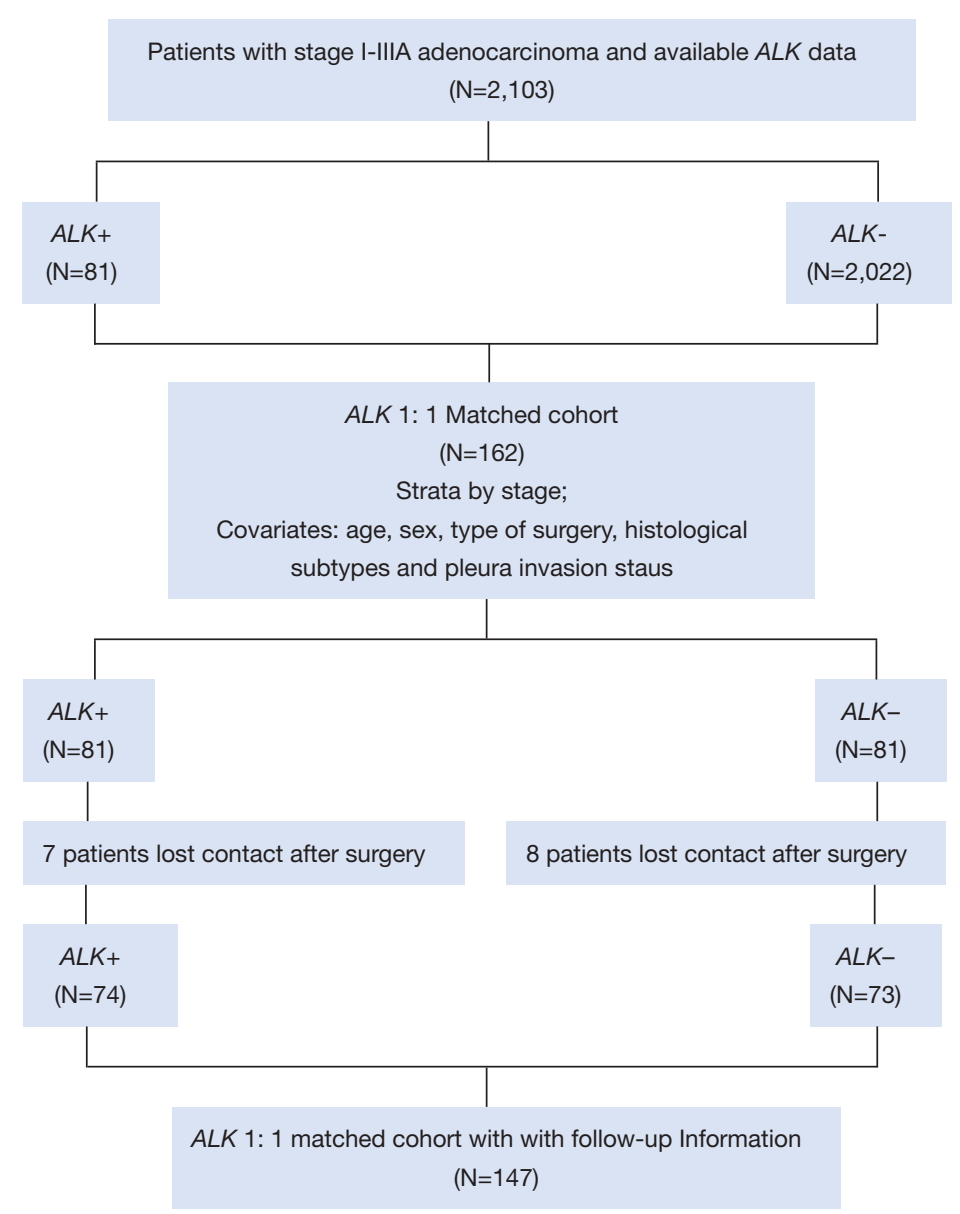

Figure 1 Patients flow diagram. $A L K$, anaplastic lymphoma kinase; $A L K+, A L K$ positive group; $A L K-, A L K$ negative group.

$210(10.0 \%)$, and stage IIIA in $254(12.1 \%)$. Invasive adenocarcinoma is the only histopathologic subtypes of the whole cohort with lepidic predominant, acinar predominant, papillary predominant, micropapillary predominant, and solid predominant subtypes present in 114 (5.4\%), 1,139 (54.2\%), $525(25.0 \%), 16(0.8 \%)$, and $179(8.5 \%)$ patients, respectively, and variants of invasive adenocarcinoma in 130 patients $(6.2 \%)$. Pleura invasion occurred in 571 (27.2\%) patients.

$A L K$ positivity was significantly associated with younger age (median age, 53 years in the $A L K$ positive group vs. 60 years in the $A L K$ negative group; $\mathrm{P}<0.001$ ), solid predominant adenocarcinoma $(\mathrm{P}<0.001)$, variants of invasive adenocarcinoma $(\mathrm{P}<0.001)$, higher frequency of pleura invasion $(\mathrm{P}=0.040)$, smaller tumor size(median size, $1.8 \mathrm{~cm}$ in the $A L K$ positive group $v s .2 .0 \mathrm{~cm}$ in the $A L K$ negative group; $\mathrm{P}=0.014)$, mediastinal lymph node involvement $(\mathrm{N} 2$; $\mathrm{P}<0.001$ ), later pathologic stage (IIIA; $\mathrm{P}=0.001$ ) (Table 1).
However, there were no significant associations between $A L K$ status and other factors such as sex $(\mathrm{P}=0.769)$, smoking status $(\mathrm{P}=0.911)$, and pathologic tumor stage $(\mathrm{P}=0.169)$ (Table 1).

\section{Clinicopathologic characteristics baseline data before and after weighting}

Table 1 also shows the clinicopathologic characteristics baseline of the patients after PSM with follow-up information. A total of 81 (3.9\%) and 2,022 (96.1\%) patients were assigned to the $A L K$ positive group and $A L K$ negative group, respectively. Before PSM, differences were observed in terms of age $(\mathrm{P}<0.001)$, adenocarcinoma subtypes $(\mathrm{P}<0.001)$, pleura invasion status $(\mathrm{P}=0.040)$, tumor size $(\mathrm{P}=0.014)$, pN stage $(\mathrm{P}<0.001)$, pTNM stage $(\mathrm{P}<0.001)$ (Table 1); after PSM, the results were similar between the two groups $(\mathrm{P}>0.05)$ except for tumor size $(\mathrm{P}=0.028)$ 
Table 1 Patients' clinicopathologic characteristics baseline before and after PSM with follow-up information

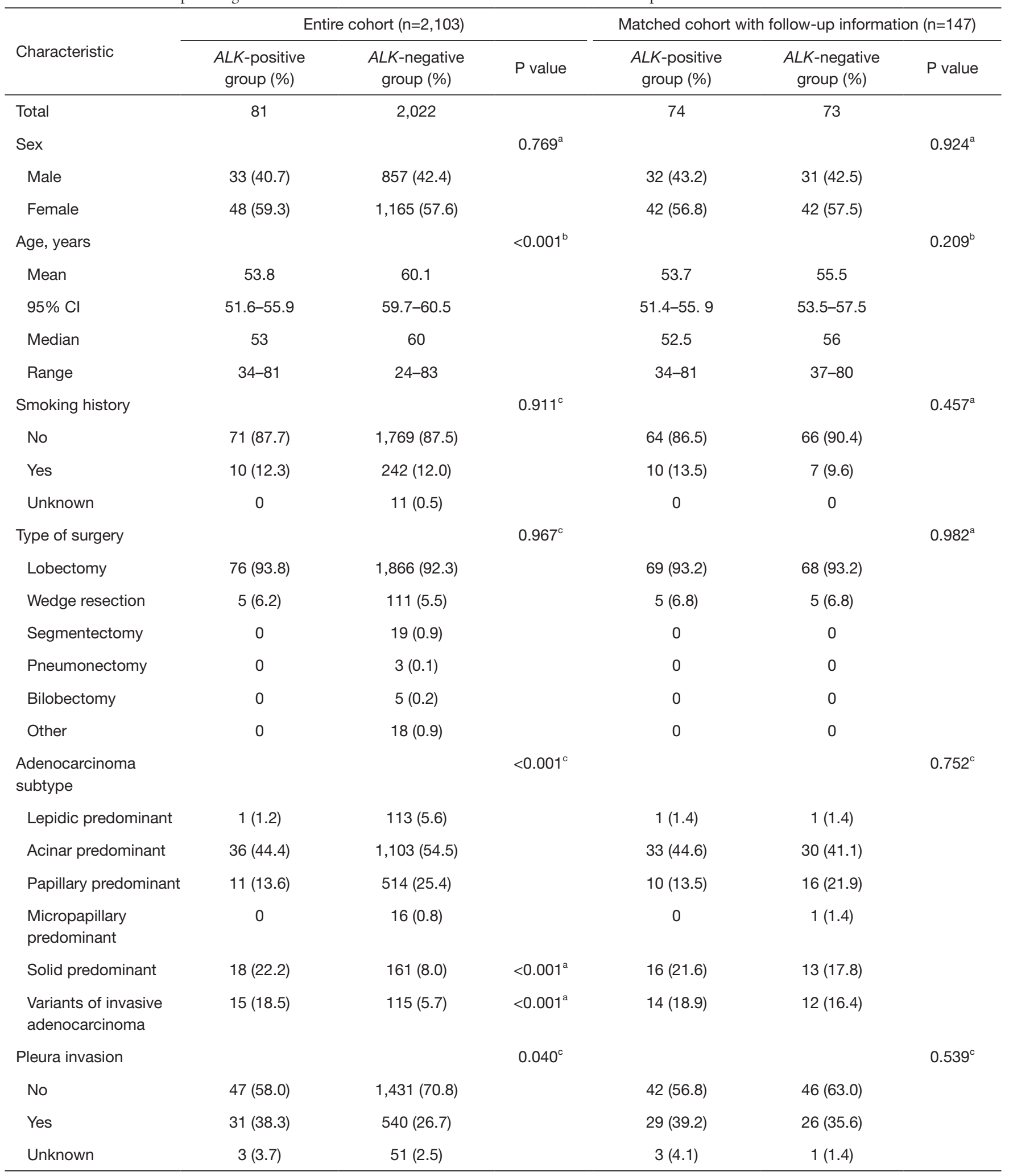

Table 1 (continued) 
Table 1 (continued)

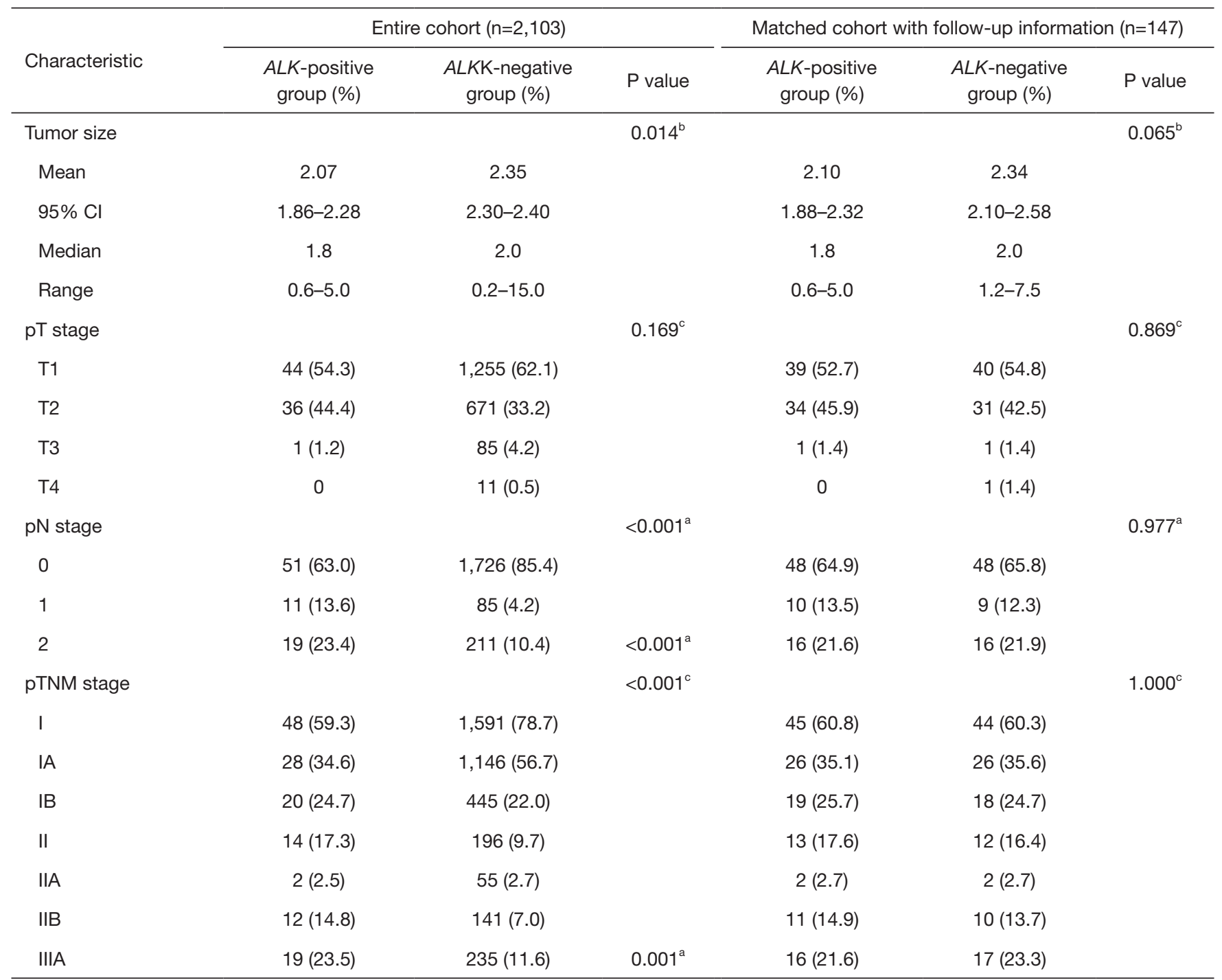

${ }^{\mathrm{a}}$, chi-square tests; ${ }^{\mathrm{b}}$, Mann-Whitney U tests; ${ }^{\mathrm{c}}$, Fisher's exact tests. PSM, propensity score matching; ALK, anaplastic lymphoma kinase;

$\mathrm{Cl}$, confidence interval; $\mathrm{pN}$ stage, pathologic nodal stage; $\mathrm{pT}$ stage, pathologic tumor stage.

(Table S1), and after the follow-up with 7 patients in the $A L K$ positive group and 8 patients in the $A L K$ negative group losing contact after surgery, the results were still similar between the two groups in the remaining 147 patients even for tumor size $(\mathrm{P}>0.05$; Table 1$)$.

\section{Prognostic value of the ALK rearrangement in completely- resected stage I-IIIA lung adenocarcinoma}

We next evaluated the associations between $A L K$ rearrangement and prognosis in the 147 completelyresected stage I-IIIA lung adenocarcinoma patients.
At the time of analysis, the median follow-up time was 55.3 months (interquartile range, 51.6 to 60.2 months). At last follow-up evaluation, a total of 18 (12.2\%) of 147 patients died and all deaths were tumor-related, with a 4 -year OS rate of $90.5 \%$. The median OS time is not yet reached. A total of $55(37.4 \%)$ of 147 patients experienced a DFS event, with a 4 -year DFS rate of $64.0 \%$. The median DFS time was also not yet reached.

The 4-year DFS rates were $66.2 \%$ in the $A L K$ positive group and $61.9 \%$ in the $A L K$ negative group. The 4-year OS rates in $A L K$ positive and negative group were $94.6 \%$ and $86.3 \%$, respectively. The median DFS and median 
A

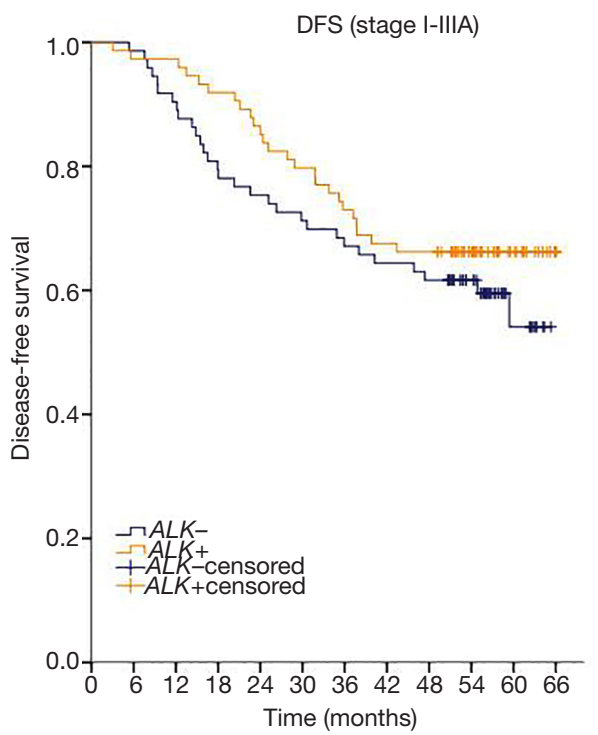

\begin{tabular}{|l|l|l|l|l|l|l|l|l|l|l|l|l|}
\hline No. at risk & & & & & & & & & & & & \\
\hline ALK+ & 74 & 72 & 72 & 68 & 63 & 59 & 54 & 50 & 49 & 49 & 49 & 49 \\
\hline ALK- & 73 & 72 & 66 & 57 & 55 & 52 & 49 & 47 & 45 & 45 & 43 & 43 \\
\hline
\end{tabular}

B

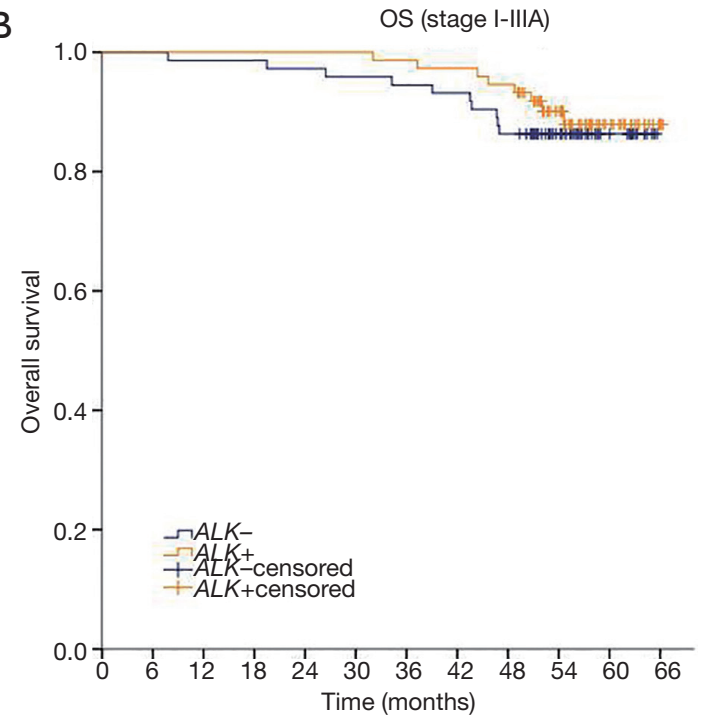

Figure 2 Kaplan-Meier survival curves for (A) DFS, and (B) OS by $A L K$ status (n=147). The median DFS and median OS of both $A L K$ positive group and $A L K$ negative group were not yet reached. The log-rank test showed that $A L K$ positivity was not associated with DFS or OS (DFS, $\mathrm{P}=0.289$; OS, $\mathrm{P}=0.549)$. $A L K$, anaplastic lymphoma kinase; DFS, disease-free survival; OS, overall survival; $A L K+, A L K$ positive group; $A L K-, A L K$ negative group.

OS of both $A L K$ positive group and $A L K$ negative group were not yet reached. The log-rank test showed that $A L K$ positivity was not associated with better DFS or OS (DFS, $\mathrm{P}=0.289$; OS, $\mathrm{P}=0.549$; Figure 2). We further analyzed the associations between $A L K$ positivity and prognosis by pathologic stage. The median OS of both $A L K$ positive group and $A L K$ negative group were not yet reached in each stage. The median DFS of both two groups was not reached in stage I. The median DFS of $A L K$ positive group and $A L K$ negative group is not reached and 54.8 months respectively in stage II. The median DFS of $A L K$ positive group and $A L K$ negative group is 35.2 and 15.9 months respectively in stage IIIA. The log-rank test still showed no significantly difference of DFS and OS between $A L K$ positive group and $A L K$ negative group in each stage (I: DFS, $\mathrm{P}=0.535$; OS, $\mathrm{P}=0.565$; II: DFS, $\mathrm{P}=0.903$; OS, $\mathrm{P}=0.338$; IIIA: DFS, $\mathrm{P}=0.138$; OS, $\mathrm{P}=0.068$; respectively).

A univariate analysis showed that disease free survival was significantly shorter in patients with high lymph node status (N2) (HR: 5.07, 95\% CI: 2.93-8.60, $\mathrm{P}<0.001$;
Table 2) or solid predominant adenocarcinoma subtype (HR: 2.22, 95\% CI: 1.25-3.93, P=0.006; Table 2). And lymph node status was the only prognostic factor of OS (HR: 6.87, 95\% CI: 2.66-17.74, $\mathrm{P}<0.001$; Table 2). ALK positivity was not associated with better DFS or OS (HR, $0.75 ; 95 \% \mathrm{CI}$ : 0.44-1.28; $\mathrm{P}=0.291$; HR: 0.75, 95\% CI: 0.30-1.91, $\mathrm{P}=0.551$, respectively; Table 2). A multivariate analysis using a Cox proportional hazards model compared survival between $A L K$ positive and $A L K$ negative patients. After adjusting for sex, age, smoking history, adenocarcinoma subtypes, pathologic nodal staging, tumor staging and $A L K$ rearrangement status, the variables that remained significantly associated with decreased DFS were mediastinal lymph node involvement (HR: 5.36, 95\% CI: 3.01-9.65, $\mathrm{P}<0.001$; Table 2) and solid predominant adenocarcinoma subtype (HR, 2.02; 95\% CI: $1.07-3.79$; $\mathrm{P}=0.029$; Table 2 ). ALK positivity was not associated with DFS (HR, 0.58; 95\% CI: 0.33-1.03, $\mathrm{P}=0.063$; Table 2) or OS (HR, 0.61; 95\% CI: 0.22-1.67, $\mathrm{P}=0.334$; Table 2). These results suggested that $A L K$ rearrangement may not be a prognostic factor in completely 


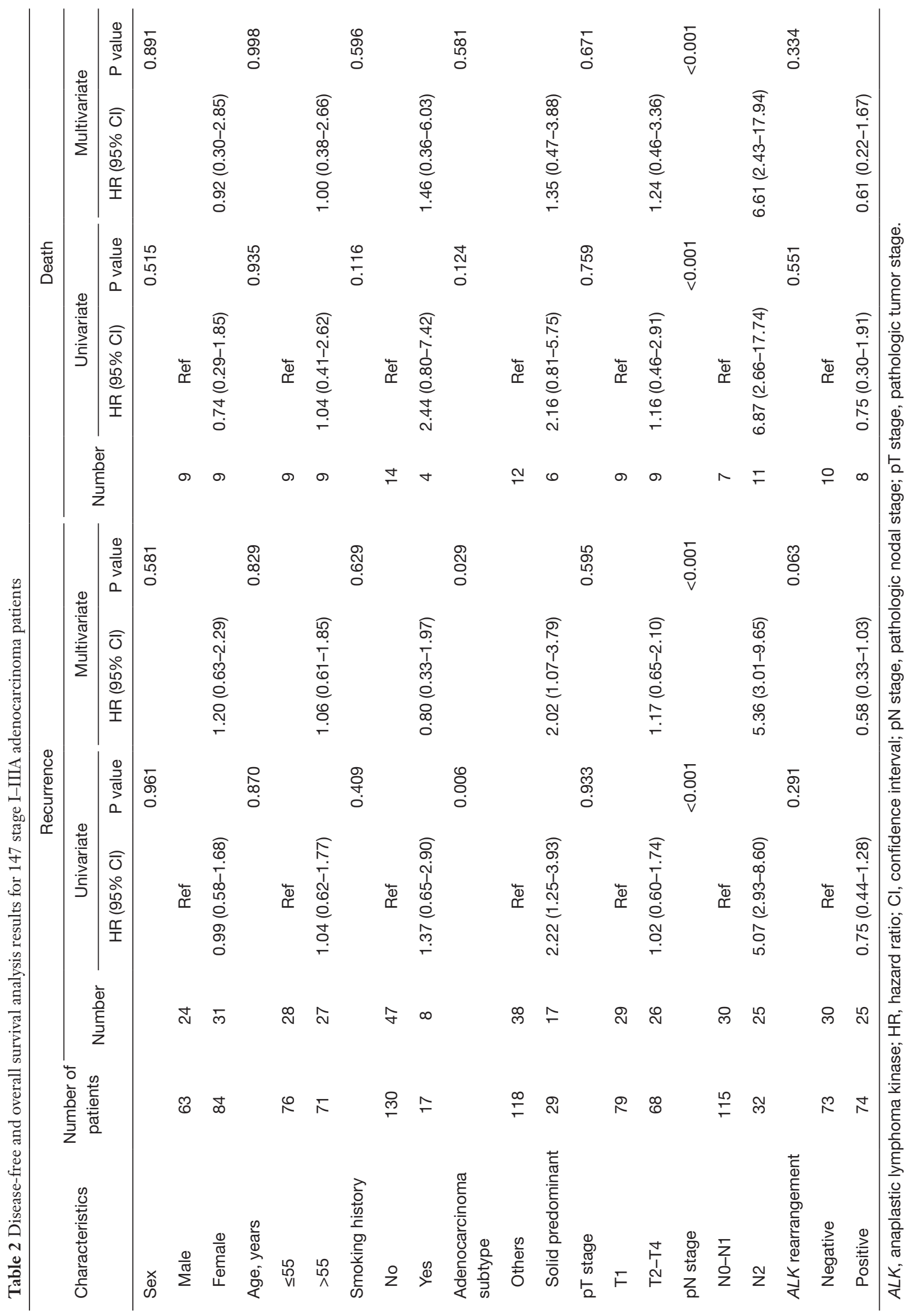




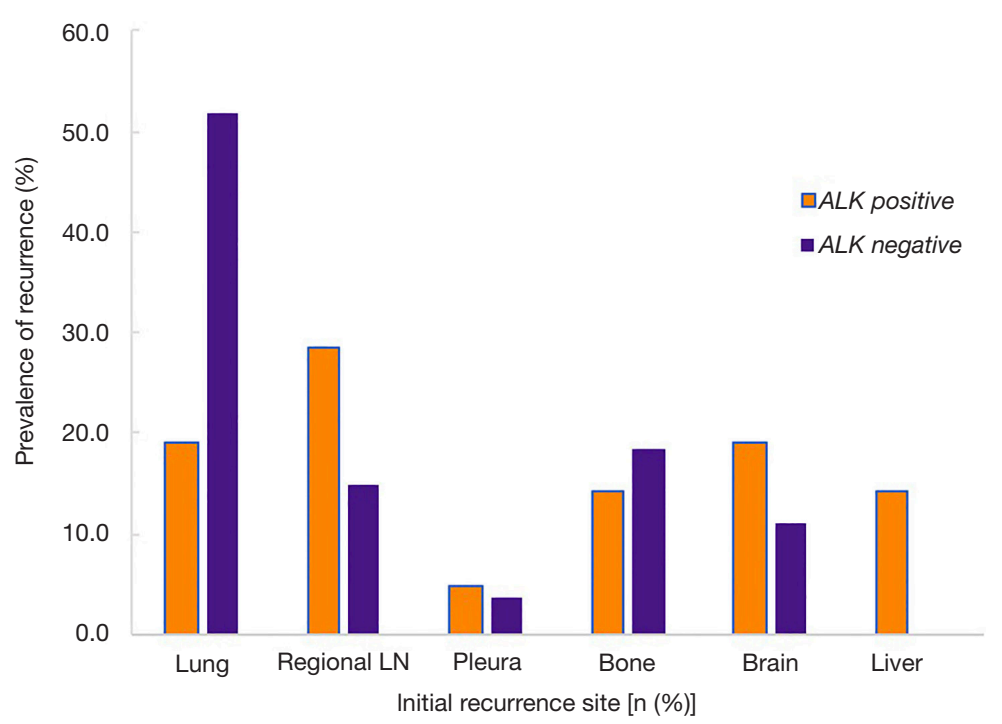

\begin{tabular}{|l|c|c|c|c|c|c|}
\hline ALK positive, $\mathrm{n}=21(\%)$ & $4(19.0)$ & $6(28.5)$ & $1(4.8)$ & $3(14.3)$ & $4(19.0)$ & $3(14.3)$ \\
\hline ALK negative, $\mathrm{n}=27(\%)$ & $14(51.9)$ & $4(14.8)$ & $1(3.7)$ & $5(18.5)$ & $3(11.1)$ & 0 \\
\hline $\mathrm{P}$ value & 0.020 & 0.244 & 0.856 & 0.696 & 0.440 & 0.043 \\
\hline
\end{tabular}

Figure 3 Initial recurrence site according to ALK IHC status among 48 patients with tumor recurrence (7 patients with multiple recurrence sites detected at the same time were excluded). ALK, anaplastic lymphoma kinase; LN, lymph node; IHC, immunohistochemistry.

resected stage I-IIIA lung adenocarcinoma.

\section{The association of ALK positivity with the initial recurrence site}

There were 55 patients with recurrent tumor in the matched cohort with follow up information. And 7 patients detected multiple recurrence sites at the same time and it was hard to find out what was really the initial site of these patients. In this case, we analyzed the association of $A L K$ positivity with initial recurrence site in the remaining 48 patients with mono recurrence site. As shown in Figure 3, we found that there was an association between $A L K$ status and liver and lung recurrence, more patients experienced liver recurrence and less experienced lung recurrence in $A L K$ positive group than in $A L K$ negative group [14.3\% (3/21) vs. $0 \%$ (0/27), $\mathrm{P}=0.043 ; 19.0 \%$ (4/21) vs. 51.9\% (14/27), $\mathrm{P}=0.020$, respectively, Figure 3]. There were no differences of other initial recurrence sites including regional lymph nodes, pleura, bone and brain between the two groups.

\section{Discussion}

The prevalence of $A L K$ positive patients was $3.9 \%$ in our study, consistent with the previous reports looking at unselected populations with mostly advanced adenocarcinoma (3-6). Several studies showed a higher prevalence of $A L K$ positivity in younger patients, light smokers or never-smokers, females $(15,16,28,30,37)$, and solid predominant adenocarcinoma subtype $(14,38,39)$. In this study, we also found $A L K$ rearrangements were detected more frequently in younger age patients and solid predominant adenocarcinoma subtype. However, ALK positivity showed no association with sex or smoking status, in accord with the results reported in other two studies $(10,14)$. Although several previous studies showed that $A L K$ rearrangement was not related to pleural invasion, we found $A L K$ positive patients tend to have pleural invasion more frequently compared with $A L K$ negative patients. A recent meta-analysis concluded that $A L K$ rearrangement was more common in higher pathologic stages (40), which is in line with our results (IIIA, $\mathrm{P}=0.001$ ). Furthermore, a previous study found that $A L K$ positive lung cancer showed earlier tumor stage (T1) $(\mathrm{P}=0.02)(8)$, whereas it tended to harbor lymph node metastasis in adenocarcinoma $(\mathrm{P}=0.09)$, which is also consistent with our results. We revealed that $A L K$ positive patients were more likely to have smaller tumor size $(\mathrm{P}=0.014)$ and mediastinal lymph node involvement 
$(\mathrm{P}<0.001)$. However, no significant difference of pathologic tumor stage $(\mathrm{P}=0.169)$ between $A L K$ positive and negative group was observed in our study.

The prognostic value of $A L K$ rearrangement in early stage NSCLC is controversial. Tantraworasin (10), Paik (8), Fukui (29), and Ohba (12), demonstrated that $A L K$ positivity was not correlated with prognosis, which is consistent with our results. Conversely, five reports revealed that patients with $A L K$ rearrangement NSCLC had a shorter DFS after adjusting for main prognostic clinical factors $(7,9,13,14,28)$, and two studies showed that $A L K$ positivity was not associated with OS $(9,13)$, while other two studies concluded that $A L K$ positive patients had inferior OS $(7,14)$. In contrast, Blackhall et al. reported superior RFS and OS in patients with $A L K$ positive early-stage NSCLC (11). To our knowledge, our study is one of the largest data set to report on the outcome of $A L K$ positive patients with stage I to IIIA resected lung adenocarcinoma. Since the significant discrepancies of age, adenocarcinoma subtypes, pTNM stage etc. between the $A L K$ positive group and $A L K$ negative group in the entire cohort, we used PSM method to control the confounding effects of these known prognostic factors for lung cancer recurrence before we compared the prognostic impact of $A L K$ rearrangement. And this is the first report using PSM to reveal that $A L K$ positivity is not associated with DFS or OS. It indicates that $A L K$ rearrangement is not an independent prognostic factor in stage I to IIIA completely resected lung adenocarcinoma patients.

In patients with advanced NSCLC, Shaw et al. found that $A L K$ FISH-positive patients seemed to have similar survival to that of the general population of wild-type patients lacking either $A L K$ rearrangement or $E G F R$ mutation (41), whereas in a report in patients free of Crizotinib with wild-type EGFR lung adenocarcinoma, $A L K$ rearrangement was associated with longer OS (42). As to patients with early stage NSCLC, Chaft et al. found that adjusted for stage $A L K$ rearrangement NSCLC was associated with worse RFS compared to EGFR-mutant, but not when compared to KRAS-mutant (31), In our study, among $73 A L K$ negative patients in the matched cohort, there were 19 patients with $E G F R$-mutation, 13 with $E G F R$ wild-type and 41 with unknown $E G F R$ mutational status. Adjusted for main prognostic clinical factors, $A L K$ positive patients showed better DFS compared to both EGFRmutant and EGFR wild-type patients (HR 0.29, 95\% CI: 0.14-0.61, $\mathrm{P}=0.001$; HR 0.27, 95\% CI: 0.12-0.63, $\mathrm{P}=0.002$, respectively). However, there was no significant difference of DFS between ALK positive patients and EGFR status unknown patients (HR 1.42, 95\% CI: 0.61-3.33, $\mathrm{P}=0.421$ ). These results might attribute to that EGFR status was not regularly tested in our study cohort after surgery. In this case, ALK negative patients who had already experienced recurrence were more likely to undergo the test for EGFR mutation to find out whether they could be treated with EGFR-tyrosine kinase inhibitors (TKI). This might result in significantly higher prevalence of recurrence in patients with clear EGFR status than ALK positive or unknown EGFR status patients in our study cohort. Therefore, it is plausible that the prognostic significance of ALK will alter relative to the EGFR mutational status of ALK-negative patients.

Furthermore, we found that mediastinal lymph node involvement (N2) and solid predominant adenocarcinoma subtype were independent prognostic factors of DFS, while mediastinal lymph node involvement (N2) was the independent prognostic factor of OS. Previous studies have shown that patients with solid predominant adenocarcinoma have poor prognosis (43-45), which is consistent with our results. Notably, a higher prevalence of $A L K$ positivity in mediastinal lymph node involvement $(\mathrm{P}<0.001)$ and solid predominant adenocarcinoma subtype $(\mathrm{P}<0.001)$ was found in our study. When the balance was achieved for these two factors in the matched cohort, there were no significant differences of DFS and OS between $A L K$ positive group and $A L K$ negative group. This result indicated that $A L K$ rearrangement might have an indirect impact on prognosis through its unique biologic features with early nodal metastasis and solid predominant adenocarcinoma subtype. However, when these factors were adjusted using PSM, we found $A L K$ rearrangement was not an independent prognostic factor.

Yang et al. reported that $A L K$-positive tumors might have an increased risk of brain and liver metastases compared with $A L K$-negative disease in late stage (28). In our study, we found that more patients experienced liver recurrence and less experienced lung recurrence in $A L K$ positive group than in $A L K$ negative group. This result indicated that there was an association between ALK status and liver and lung recurrence. But the risk of brain metastases was similar in two groups.

Nevertheless, our study has several limitations. Firstly, we did not analyze the survival of entire cohort and the method PSM has its intrinsic limitation including that there may be other prognostic factors not covered in our regression model. Secondly, fifteen patients were lost to 
follow-up, although the clinicopathologic characteristics were still balanced between the two groups in the remaining patients. Thirdly, the EGFR or KRAS status were unknown in more than half of $A L K$ negative patients, which made it challenging to analyze the prognostic impact of these genomic subsets. Fourthly, post-recurrence therapy information was lacking in our study and this might affect the OS of patients who experienced recurrence. In addition, since the majority of the patients in our study cohorts were woman and non-smokers, which is not typical of a non-East Asian population with lung cancer, the applicability of this study's results may be limited in North American/European population.

\section{Conclusions}

$A L K$ rearrangement was not an independent prognostic factor in stage I-IIIA lung adenocarcinoma patients, but it significantly correlated with younger age, solid predominant adenocarcinoma, higher frequency of pleura invasion, smaller tumor size, mediastinal lymph node involvement and later pathologic stage. In addition, there was an association between ALK status and liver and lung recurrence, more patients experienced liver recurrence and less experienced lung recurrence with ALK positive tumors than with ALK negative tumors.

\section{Acknowledgments}

Funding: This work was funded by the National Key R\&D Program of China (2016YFC1303300 to S Lu), the National Natural Science Foundation of China (81672272 to S Lu), the Shanghai Municipal Science \& Technology Commission Research Project (17431906103 to S Lu), the Shanghai Shenkang Action Plan (16CR3005A to S Lu), and the National Science and Technology Major Projects of New Drug Creation (2018ZX09301014-001-003 to S $\mathrm{Lu}$ ), Shanghai Economic and Information Commission for oncology data platforms (201602010).

\section{Footnote}

Conflicts of Interest: The authors have no conflicts of interest to declare.

Ethical Statement: The authors are accountable for all aspects of the work in ensuring that questions related to the accuracy or integrity of any part of the work are appropriately investigated and resolved. This study was approved by Ethics Committee of Shanghai Chest Hospital. Written informed consent was obtained from all individual participants included in this study. And this study was conducted in accordance with the Declaration of Helsinki.

\section{References}

1. Siegel RL, Miller KD, Jemal A. Cancer statistics, 2019. CA Cancer J Clin 2019;69:7-34.

2. Molina JR, Yang PG, Cassivi SD, et al. Non-small cell lung cancer: Epidemiology, risk factors, treatment, and survivorship. Mayo Clin Proc 2008;83:584-94.

3. Tsao AS, Scagliotti GV, Bunn PA, et al. Scientific Advances in Lung Cancer 2015. J Thorac Oncol 2016;11:613-38.

4. Kwak EL, Bang YJ, Camidge DR, et al. Anaplastic Lymphoma Kinase Inhibition in Non-Small-Cell Lung Cancer. New Engl J Med 2010;363:1693-703.

5. Barlesi F, Mazieres J, Merlio JP, et al. Routine molecular profiling of patients with advanced non-small-cell lung cancer: results of a 1-year nationwide programme of the French Cooperative Thoracic Intergroup (IFCT). Lancet 2016;387:1415-26.

6. Vidal J, Clave S, de Muga S, et al. Assessment of ALK Status by FISH on 1000 Spanish Non-Small Cell Lung Cancer Patients. J Thorac Oncol 2014;9:1816-20.

7. Kim HR, Shim HS, Chung JH, et al. Distinct clinical features and outcomes in never-smokers with non-small cell lung cancer who harbor EGFR or KRAS mutations or ALK rearrangement. Cancer 2012;118:729-39.

8. Paik JH, Choi CM, Kim H, et al. Clinicopathologic implication of ALK rearrangement in surgically resected lung cancer A proposal of diagnostic algorithm for ALKrearranged adenocarcinoma. Lung Cancer 2012;76:403-9.

9. Kim MH, Shim HS, Kang DR, et al. Clinical and prognostic implications of ALK and ROS1 rearrangements in never-smokers with surgically resected lung adenocarcinoma. Lung Cancer 2014;83:389-95.

10. Tantraworasin A, Lertprasertsuke N, Kongkarnka S, et al. Retrospective Study of ALK Rearrangement and Clinicopathological Implications in Completely Resected Non-small Cell Lung Cancer Patients in Northern Thailand: Role of Screening with D5F3 Antibodies. Asian Pac J Cancer Prev 2014;15:3057-63.

11. Blackhall FH, Peters S, Bubendorf L, et al. Prevalence and Clinical Outcomes for Patients With ALK-Positive Resected Stage I to III Adenocarcinoma: Results From the European Thoracic Oncology Platform Lungscape 
Project. J Clin Oncol 2014;32:2780-+.

12. Ohba T, Toyokawa G, Osoegawa A, et al. Mutations of the EGFR, K-ras, EML4-ALK, and BRAF genes in resected pathological stage I lung adenocarcinoma. Surgery Today 2016;46:1091-8.

13. Shin SH, Lee H, Jeong BH, et al. Anaplastic lymphoma kinase rearrangement in surgically resected stage IA lung adenocarcinoma. J Thorac Dis 2018;10:3460-7.

14. Gao Q, Li P, Jiang X, et al. Worse disease-free, tumorspecific, and overall survival in surgically-resected lung adenocarcinoma patients with ALK rearrangement. Oncotarget 2017;8:86066-81.

15. Rodig SJ, Mino-Kenudson M, Dacic S, et al. Unique Clinicopathologic Features Characterize ALK-Rearranged Lung Adenocarcinoma in the Western Population. Clin Cancer Res 2009;15:5216-23.

16. Shaw AT, Yeap BY, Mino-Kenudson M, et al. Clinical Features and Outcome of Patients With Non-Small-Cell Lung Cancer Who Harbor EML4-ALK. J Clin Oncol 2009;27:4247-53.

17. Sacher AG, Dahlberg SE, Heng J, et al. Association Between Younger Age and Targetable Genomic Alterations and Prognosis in Non-Small-Cell Lung Cancer. JAMA Oncol 2016;2:313-20.

18. Popat S, Gonzalez D, Min T, et al. ALK translocation is associated with ALK immunoreactivity and extensive signet-ring morphology in primary lung adenocarcinoma. Lung Cancer 2012;75:300-5.

19. Gainor JF, Varghese AM, Ou SHI, et al. ALK Rearrangements Are Mutually Exclusive with Mutations in EGFR or KRAS: An Analysis of 1,683 Patients with Non-Small Cell Lung Cancer. Clin Cancer Res 2013;19:4273-81.

20. Morris SW, Kirstein MN, Valentine MB, et al. Fusion of a kinase gene, ALK, to a nucleolar protein gene, NPM, in non-Hodgkin's lymphoma. Science 1994;263:1281-4.

21. Soda M, Choi YL, Enomoto M, et al. Identification of the transforming EML4-ALK fusion gene in non-small-cell lung cancer. Nature 2007;448:561-6.

22. Woo CG, Seo S, Kim SW, et al. Differential protein stability and clinical responses of EML4-ALK fusion variants to various ALK inhibitors in advanced ALKrearranged non-small cell lung cancer. Ann Oncol 2017;28:791-7.

23. Yoshida T, Oya Y, Tanaka K, et al. Differential Crizotinib Response Duration Among ALK Fusion Variants in ALKPositive Non-Small-Cell Lung Cancer. J Clin Oncol 2016;34:3383-9.
24. Rikova K, Guo A, Zeng Q, et al. Global survey of phosphotyrosine signaling identifies oncogenic kinases in lung cancer. Cell 2007;131:1190-203.

25. Takeuchi K, Choi YL, Togashi Y, et al. KIF5BALK, a novel fusion oncokinase identified by an immunohistochemistry-based diagnostic system for ALKpositive lung cancer. Clin Cancer Res 2009;15:3143-9.

26. Chiarle R, Voena C, Ambrogio C, et al. The anaplastic lymphoma kinase in the pathogenesis of cancer. Nat Rev Cancer 2008;8:11-23.

27. Soda M, Takada S, Takeuchi K, et al. A mouse model for EML4-ALK-positive lung cancer. Proc Natl Acad Sci U S A 2008;105:19893-7.

28. Yang P, Kulig K, Boland JM, et al. Worse DiseaseFree Survival in Never-Smokers with ALK plus Lung Adenocarcinoma. J Thorac Oncol 2012;7:90-7.

29. Fukui T, Yatabe Y, Kobayashi Y, et al. Clinicoradiologic characteristics of patients with lung adenocarcinoma harboring EML4-ALK fusion oncogene. Lung Cancer 2012;77:319-25.

30. Camidge DR, Bang YJ, Kwak EL, et al. Activity and safety of crizotinib in patients with ALK-positive non-small-cell lung cancer: updated results from a phase 1 study. Lancet Oncol 2012;13:1011-9.

31. Chaft JE, Dagogo-Jack I, Santini FC, et al. Clinical outcomes of patients with resected, early-stage ALKpositive lung cancer. Lung Cancer 2018;122:67-71.

32. McDermott U, Iafrate AJ, Gray NS, et al. Genomic alterations of anaplastic lymphoma kinase may sensitize tumors to anaplastic lymphoma kinase inhibitors. Cancer Res 2008;68:3389-95.

33. Shaw AT, Kim DW, Nakagawa K, et al. Crizotinib versus Chemotherapy in Advanced ALK-Positive Lung Cancer. New Engl J Med 2013;368:2385-94.

34. Solomon BJ, Mok T, Kim DW, et al. First-Line Crizotinib versus Chemotherapy in ALK-Positive Lung Cancer. New Engl J Med 2014;371:2167-77.

35. Shaw AT, Kim DW, Mehra R, et al. Ceritinib in ALKrearranged non-small-cell lung cancer. N Engl J Med 2014;370:1189-97.

36. Yang JCH, Ou SHI, De Petris L, et al. Pooled Systemic Efficacy and Safety Data from the Pivotal Phase II Studies (NP28673 and NP28761) of Alectinib in ALKpositive Non-Small Cell Lung Cancer. J Thorac Oncol 2017;12:1552-60.

37. Camidge DR, Kono SA, Lu XA, et al. Anaplastic Lymphoma Kinase Gene Rearrangements in Nonsmall Cell Lung Cancer are Associated with Prolonged 
Progression-Free Survival on Pemetrexed. J Thorac Oncol 2011;6:774-80.

38. Possidente L, Landriscina M, Patitucci G, et al. ALK rearrangement in specific subtypes of lung adenocarcinoma: immunophenotypic and morphological features. Med Oncol 2017;34:76.

39. Dong YJ, Cai YR, Zhou LJ, et al. Association between the histological subtype of lung adenocarcinoma, EGFR/ KRAS mutation status and the ALK rearrangement according to the novel IASLC/ATS/ERS classification. Oncol Lett 2016;11:2552-8.

40. Zhao F, Xu M, Lei H, et al. Clinicopathological Characteristics of Patients with Non-Small-Cell Lung Cancer Who Harbor EML4-ALK Fusion Gene: A MetaAnalysis. PLoS One 2015;10:e117333.

41. Shaw AT, Yeap BY, Solomon BJ, et al. Effect of crizotinib on overall survival in patients with advanced non-smallcell lung cancer harbouring ALK gene rearrangement: a

Cite this article as: Liu Y, Ye X, Yu Y, Lu S. Prognostic significance of anaplastic lymphoma kinase rearrangement in patients with completely resected lung adenocarcinoma. J Thorac Dis 2019;11(10):4258-4270. doi: 10.21037/jtd.2019.09.65 retrospective analysis. Lancet Oncol 2011;12:1004-12.

42. Wu SG, Kuo YW, Chang YL, et al. EML4-ALK Translocation Predicts Better Outcome in Lung Adenocarcinoma Patients with Wild-Type EGFR. J Thorac Oncol 2012;7:98-104.

43. von der Thusen JH, Tham YS, Pattenden H, et al. Prognostic Significance of Predominant Histologic Pattern and Nuclear Grade in Resected Adenocarcinoma of the Lung Potential Parameters for a Grading System. J Thorac Oncol 2013;8:37-44.

44. Makinen JM, Laitakari K, Johnson S, et al. Nonpredominant lepidic pattern correlates with better outcome in invasive lung adenocarcinoma. Lung Cancer 2015;90:568-74.

45. Murakami S, Ito H, Tsubokawa N, et al. Prognostic value of the new IASLC/ATS/ERS classification of clinical stage IA lung adenocarcinoma. Lung Cancer 2015;90:199-204. 
Table S1 Patients' clinicopathologic characteristics baseline before and after PSM

\begin{tabular}{|c|c|c|c|c|c|c|}
\hline \multirow{2}{*}{ Characteristic } & \multicolumn{3}{|c|}{ Entire cohort $(n=2,103)$} & \multicolumn{3}{|c|}{ Matched cohort $(n=162)$} \\
\hline & $A L K$-positive group (\%) & $A L K$-negative group (\%) & $P$ value & $A L K$-positive group (\%) & ALK-negative group (\%) & $P$ value \\
\hline Total & 81 & 2,022 & & 81 & 81 & \\
\hline Sex & & & $0.769^{\mathrm{a}}$ & & & $0.873^{a}$ \\
\hline Male & $33(40.7)$ & $857(42.4)$ & & $33(40.7)$ & $32(39.5)$ & \\
\hline Female & 48 (59.3) & $1,165(57.6)$ & & 48 (59.3) & $49(60.5)$ & \\
\hline Age, years & & & $<0.001^{\mathrm{b}}$ & & & $0.289^{b}$ \\
\hline Mean & 53.8 & 60.1 & & 53.8 & 55.4 & \\
\hline $95 \% \mathrm{Cl}$ & $51.6-55.9$ & $59.7-60.5$ & & $51.6-56.0$ & $53.5-57.3$ & \\
\hline Median & 53 & 60 & & 53 & 56 & \\
\hline Range & $34-81$ & $24-83$ & & $34-81$ & $37-80$ & \\
\hline Smoking history & & & $0.911^{c}$ & & & $0.430^{\circ}$ \\
\hline No & $71(87.7)$ & 1,769 (87.5) & & $71(87.7)$ & $74(91.4)$ & \\
\hline Yes & $10(12.3)$ & $242(12.0)$ & & $10(12.3)$ & $6(7.4)$ & \\
\hline Unknown & 0 & $11(0.5)$ & & 0 & $1(1.2)$ & \\
\hline Type of surgery & & & $0.967^{\circ}$ & & & $1.000^{a}$ \\
\hline Lobectomy & $76(93.8)$ & $1,866(92.3)$ & & $76(93.8)$ & $76(93.8)$ & \\
\hline Wedge resection & $5(6.2)$ & $111(5.5)$ & & $5(6.2)$ & $5(6.2)$ & \\
\hline Segmentectomy & 0 & $19(0.9)$ & & 0 & 0 & \\
\hline Pneumonectomy & 0 & $3(0.1)$ & & 0 & 0 & \\
\hline Bilobectomy & 0 & $5(0.2)$ & & 0 & 0 & \\
\hline Other & 0 & $18(0.9)$ & & 0 & 0 & \\
\hline Adenocarcinoma subtype & & & $<0.001^{\mathrm{c}}$ & & & $0.694^{\mathrm{c}}$ \\
\hline Lepidic predominant & $1(1.2)$ & $113(5.6)$ & & $1(1.2)$ & $1(1.2)$ & \\
\hline Acinar predominant & $36(44.4)$ & $1,103(54.5)$ & & $36(44.4)$ & $33(40.7)$ & \\
\hline Papillary predominant & $11(13.6)$ & $514(25.4)$ & & $11(13.6)$ & $18(22.2)$ & \\
\hline Micropapillary predominant & 0 & $16(0.8)$ & & 0 & $1(1.2)$ & \\
\hline Solid predominant & $18(22.2)$ & $161(8.0)$ & $<0.001^{a}$ & $18(22.2)$ & $15(18.5)$ & \\
\hline Variants of invasive adenocarcinoma & $15(18.5)$ & $115(5.7)$ & $<0.001^{\mathrm{a}}$ & $15(18.5)$ & $13(16.0)$ & \\
\hline Pleura invasion & & & $0.040^{\mathrm{c}}$ & & & $0.763^{\mathrm{c}}$ \\
\hline No & $47(58.0)$ & $1,431(70.8)$ & & $47(58.0)$ & $50(61.7)$ & \\
\hline Yes & 31 (38.3) & $540(26.7)$ & & 31 (38.2) & 28 (34.6) & \\
\hline Unknown & $3(3.7)$ & $51(2.5)$ & & $3(3.7)$ & $3(3.7)$ & \\
\hline Tumor size & & & $0.014^{\mathrm{b}}$ & & & $0.028^{b}$ \\
\hline Mean & 2.07 & 2.35 & & 2.08 & 2.34 & \\
\hline $95 \% \mathrm{Cl}$ & $1.86-2.28$ & $2.30-2.40$ & & $1.86-2.28$ & $2.12-2.56$ & \\
\hline Median & 1.8 & 2.000 & & 1.8 & 2.0 & \\
\hline Range & $0.6-5.0$ & $0.2-15.0$ & & $0.6-5.0$ & $1.0-7.5$ & \\
\hline pT stage & & & $0.169^{c}$ & & & $0.811^{\mathrm{c}}$ \\
\hline $\mathrm{T} 1$ & $44(54.3)$ & $1,255(62.1)$ & & 44 (54.3) & 45 (55.6) & \\
\hline T2 & $36(44.4)$ & $671(33.2)$ & & $36(44.4)$ & $33(40.7)$ & \\
\hline T3 & $1(1.2)$ & $85(4.2)$ & & $1(1.2)$ & $2(2.5)$ & \\
\hline $\mathrm{T} 4$ & 0 & $11(0.5)$ & & 0 & $1(1.2)$ & \\
\hline $\mathrm{pN}$ stage & & & $<0.001^{a}$ & & & $0.885^{a}$ \\
\hline 0 & $51(63.0)$ & 1,726 (85.4) & & $51(63.0)$ & $54(66.7)$ & \\
\hline 1 & 11 (13.6) & $85(4.2)$ & & 11 (13.6) & 10 (12.3) & \\
\hline 2 & 19 (23.4) & $211(10.4)$ & & $19(23.4)$ & $17(21.0)$ & \\
\hline pTNM stage & & & $<0.001^{\mathrm{c}}$ & & & $1.000^{\circ}$ \\
\hline 1 & 48 (59.3) & $1,591(78.7)$ & & 48 (59.3) & 48 (59.3) & \\
\hline IA & 28 (34.6) & $1,146(56.7)$ & & 28 (34.6) & 28 (34.6) & \\
\hline IB & $20(24.7)$ & 445 (22.0) & & $20(24.7)$ & $20(24.7)$ & \\
\hline II & $14(17.3)$ & $196(9.7)$ & & $14(17.3)$ & $14(17.3)$ & \\
\hline$\| \mathrm{A}$ & $2(2.5)$ & $55(2.7)$ & & $2(2.5)$ & $2(2.5)$ & \\
\hline IIB & $12(14.8)$ & $141(7.0)$ & & $12(14.8)$ & $12(14.8)$ & \\
\hline IIIA & $19(23.5)$ & 235 (11.6) & $0.001^{\mathrm{a}}$ & $19(23.5)$ & $19(23.5)$ & \\
\hline
\end{tabular}

a, chi-square tests; ${ }^{\mathrm{b}}$, Mann-Whitney $\mathrm{U}$ tests; ${ }^{\mathrm{c}}$, Fisher's exact tests. PSM, propensity score matching; $A L K$, anaplastic lymphoma kinase; $\mathrm{Cl}$, confidence interval; pN stage, pathologic nodal stage; pT stage, pathologic tumor stage. 